\title{
Defined Experimental Unit Allocation
}

National Cancer Institute

\section{Source}

National Cancer Institute. Defined Experimental Unit Allocation. NCI Thesaurus. Code C93369.

An administrative activity defined at a global library level that is the assignment of an experimental unit to a portion of the study, such as an arm or a portion of an arm (when secondary allocations may occur). 